\title{
Hemmwirkung von Aureomycin auf holzbesiedelnde Prüfpilze
}

J. G. Rutiaga Quiñones, P. Schumacher, S. Hüttl Institut für Holzforschung der Universität München, Winzererstr. 45, D-80797 München, Germany

Subject The antibiotic Aureomycin was found to supress bacteria completety at a concentration of $20 \mathrm{ppm}$ in malt agar while rate of growth of the fungal test species Trametes versicolor, Coniophora puteana, Chaetomium globosum and Trichoderma viride was only affected at concentrations above $50 \mathrm{ppm}$.

Bei der Kultivierung holzbesiedelnder Prüfpilze in vitro tritt nicht selten eine Kontamination der Kulturen durch Bakterien auf. Zu ihrer Unterdrückung können dem Nährmedium Antibiotika zugesetzt werden, wobei jedoch insbesondere bei Überdosierung unerwünschte Hemmwirkungen auf das Wachstum und die Abbauleistung der Pilze sowie Degenerationserscheinungen zu befürchten sind.

An vier häufig verwendeten Prüfpilzen wurde die Hemmwirkung des Breitbandantibiotikums Aureomycin auf das Wachstum in Abhängigkeit von der Konzentration getestet. Die Versuche wurden mit mehreren Wiederholungen in Petrischalen auf $2 \%$ Malzagar bei $21^{\circ} \mathrm{C}$ durchgeführt.

Ergebnisse Alle vier Pilzarten zeigten mit steigender AureomycinKonzentration eine zunehmende Verlangsamung der

Wuchsgeschwindigkeit im Vergleich zur Nullvariante (Bild), wobe Chaetomium globosum am empfindlichsten reagierte, während Coniophora puteana erst bei über 150 ppm deutlich abfiel. Trametes versicolor und Trichoderma viride erwiesen sich hingegen als verhältnismäßig unempfindlich. Eine deutliche Hemmwirkung auf die Prüfpilze ergab sich stets erst bei Konzentrationen oberhalb von 50 ppm Aureomycin im Agar, während eine zuverlässige Unterdrückung von Bakterien noch bei $20 \mathrm{ppm}$ möglich war. Aureomycin erscheint daher zur Bakterienunterdrückung in einer Konzentration von $20 \mathrm{ppm}$ als ausreichend wirksam und für die Vitalität obengenannter Prüfpilze noch verhältnismäßig unbedenklich.

Bild 1. Vergleich des radialen Wachstums von Chaetomium globosum, Coniophora puteana, Trametes versicolor und Trichoderma viride auf $2 \%$ Malzagar in Petrischalen in Abhängigkeit von der Aureomycin-

Konzentration (ppm) im Nährmedium und der Zeit ab Inokulation Fig. 1. Comparison of radial growth of Chaetomium globosum, Coniophora puteana, Trametes versicolor and Trichoderma viride on $2 \%$ malt agar in dependence of Aureomycin concentration (ppm) and time (days after inoculation)
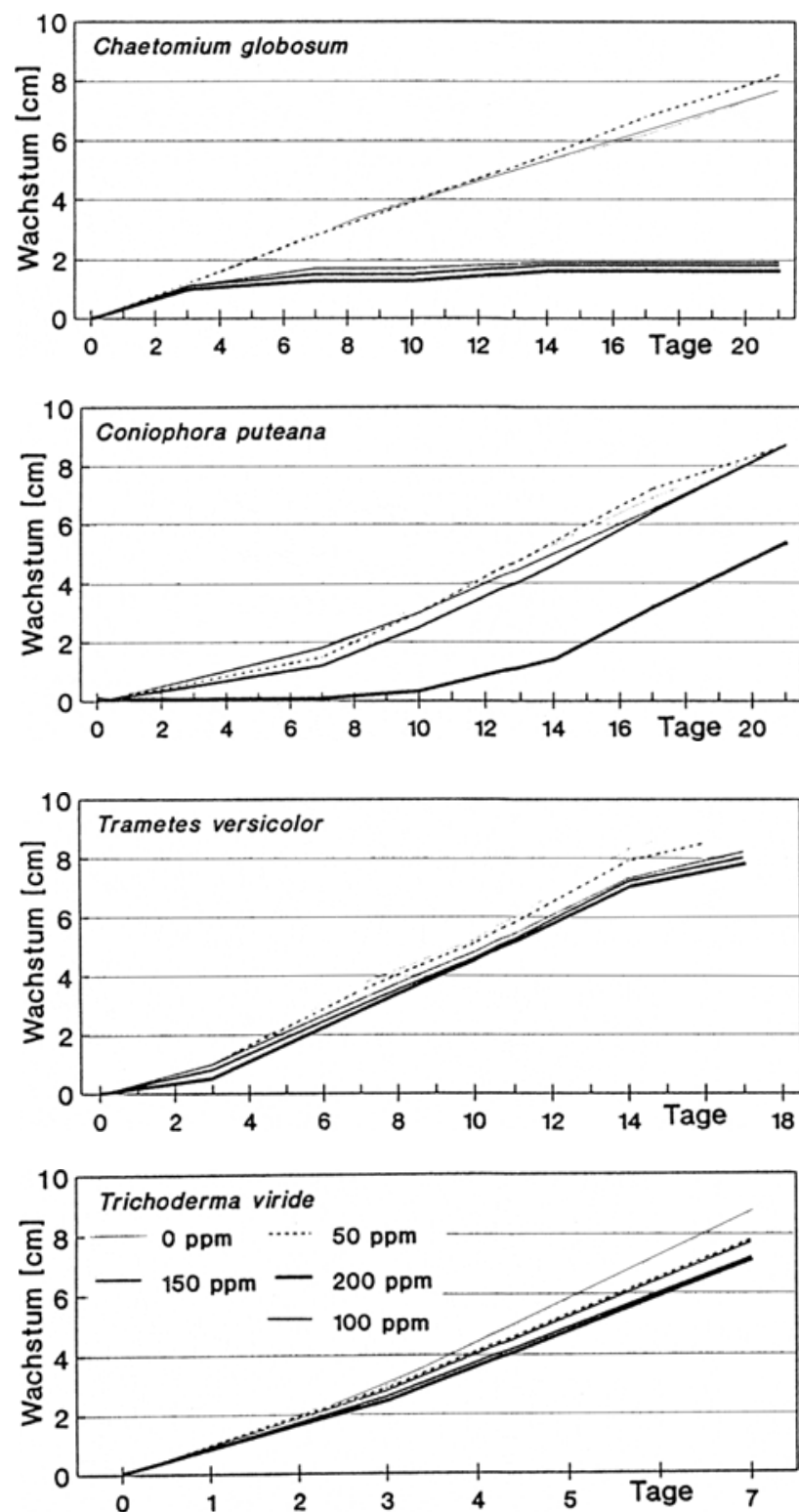